DOI: https://doi.org/10.33366/jkn.v1i1.4

\title{
Advokasi Wartawan Korban Kekerasan di Aliansi Jurnalis Independen Malang
}

\author{
Suhardi, Fathul Qorib \\ Program Studi Ilmu Komunikasi, Fisip, Universitas Tribhuwana Tunggadewi \\ Email: suhardinam@gmail.com
}

\begin{abstract}
Communication patterns occur in every organization, including the Alliance of Independent Journalists/Aliansi Jurnalis Independen (AJI) Malang in advocating journalists. Journalists who are members of AJI Malang will find it easier to overcome problems while carrying out their journalistic tasks because AJI Malang has three main issues that are always the center of attention, which are the struggle to maintain press freedom, improve journalist's professionalism, and improve the welfare of journalists. The purpose of this study was to determine the organizational communication pattern of the Alliance of Independent Journalists (AJI) Malang in advocating journalists and factors that hinder the Malang Alliance of Independent Journalists (AJI) in advocating journalists. This study used qualitative research methods. The method of data analysis used by researchers is the descriptive method, which describes the results of the data obtained.The results of the study prove that the communication pattern of the Alliance of Independent Journalists (AJI) Malang uses the primary, secondary, linear and circular communication patterns. While the factors that hinder the Malang Alliance of Independent Journalists (AJI) in advocating for journalists are two factors, which are the internal factor comes from the number of journalists who have not understood the journalistic code of ethics and stopped the case in the middle of an advocacy process. While external factors came from press companies that were less proactive in guarding advocacy by journalists.
\end{abstract}

Keywords: Alliance of Independent Journalists, advocating journalists, Media

\begin{abstract}
Abstrak: Pola komunikasi terjadi di setiap organisasi, termasuk Aliansi Jurnalis Independen (AJI) Malang dalam mengadvokasi wartawan. Wartawan yang tergabung di Aliansi Jurnlis Independen (AJI) Malang akan lebih mudah mengatasi masalah saat melaksanakan tugas jurnalistiknya, karena AJI Malang sendiri memiliki tiga isu utama yang selalu menjadi pusat perhatian yaitu, perjuangan untuk mempertahankan kebebasan pers, meningkatkan profesinalisme jurnalis, dan meningkatkan kesejahteraan jurnalis. Tujuan penelitian ini adalah untuk mengetahui pola komunikasi organisasi Aliansi Jurnalis Independen (AJI) Malang dalam mengadvokasi wartawan dan faktorfaktor yang menghambat Aliansi Jurnalis Independen (AJI) Malang dalam mengadvokasi wartawan. Penelitian ini menggunakan metode penelitian kualitatif. Metode analisa data yang digunakan peneliti yaitu metode deskriptif, dimana mendeskripsikan hasil data yang diperoleh. Hasil penelitian membuktikan jika pola komunikasi organisasi Aliansi Jurnalis Independen (AJI) Malang menggunakan pola komunikasi primer, sekunder, linier dan sirkular. Sedangkan faktor yang menghambat Aliansi Jurnalis Independen (AJI) Malang dalam mengadvokasi wartawan terdapat dua faktor yaitu, faktor internal berasal dari banyaknya wartawan yang belum memahami kode etik jurnalistik dan menghentikan kasusnya di tengah proses advokasi. Sedangkan faktor eksternal berasal dari perusahaan pers yang kurang pro aktif mengawal advokasi yang di lakukan wartawan.
\end{abstract}

Kata Kunci: Aliansi Jurnalis Independen, Advokasi Jurnalis, Media

\section{PENDAHULUAN}

Kekerasan terhadap wartawan selalu ada. Bahkan di tahun 2017, Aliansi Jurnalis Independen (AJI) secara khusus menerbitkan jurnal dengan judul besar "Perlindungan terhadap Wartawan: Pekerjaan Rumah Tanpa Akhir". Tajuk ini mengindikasikan adanya kekerasan terhadap wartawan yang terus terjadi sehingga mereka butuh dilindungi. Tidak sekali-dua kali, aktivitas melindungi wartawan ini harus dilakukan secara terus-menerus, tanpa akhir. 


\section{Jurnal Komunikasi Nusantara}

e-ISSN. 2685-7650

Vol. 1 No. 1 (2019), pp 11-19

DOI: https://doi.org/10.33366/jkn.v1i1.4

Meskipun profesi wartawan telah diatur dalam kode etik yang sangat ketat, serta dikukuhkan dalam Undang-Undang No 40 Tahun 1999, namun kekerasan terhadap wartawan terus terjadi. Data dari situs AJI menunjukan, kekerasan yang dialami wartawan di Indonesia masih tinggi. Pada tahun 2016 wartawan yang terdata oleh AJI dan mengalami kekerasan berjumlah 81 wartawan, pada tahun 2017 sebanyak 66 wartawan, dan di tahun 2018 ada 64 kasus kekerasan terhadap wartawan (Aji, 2018).

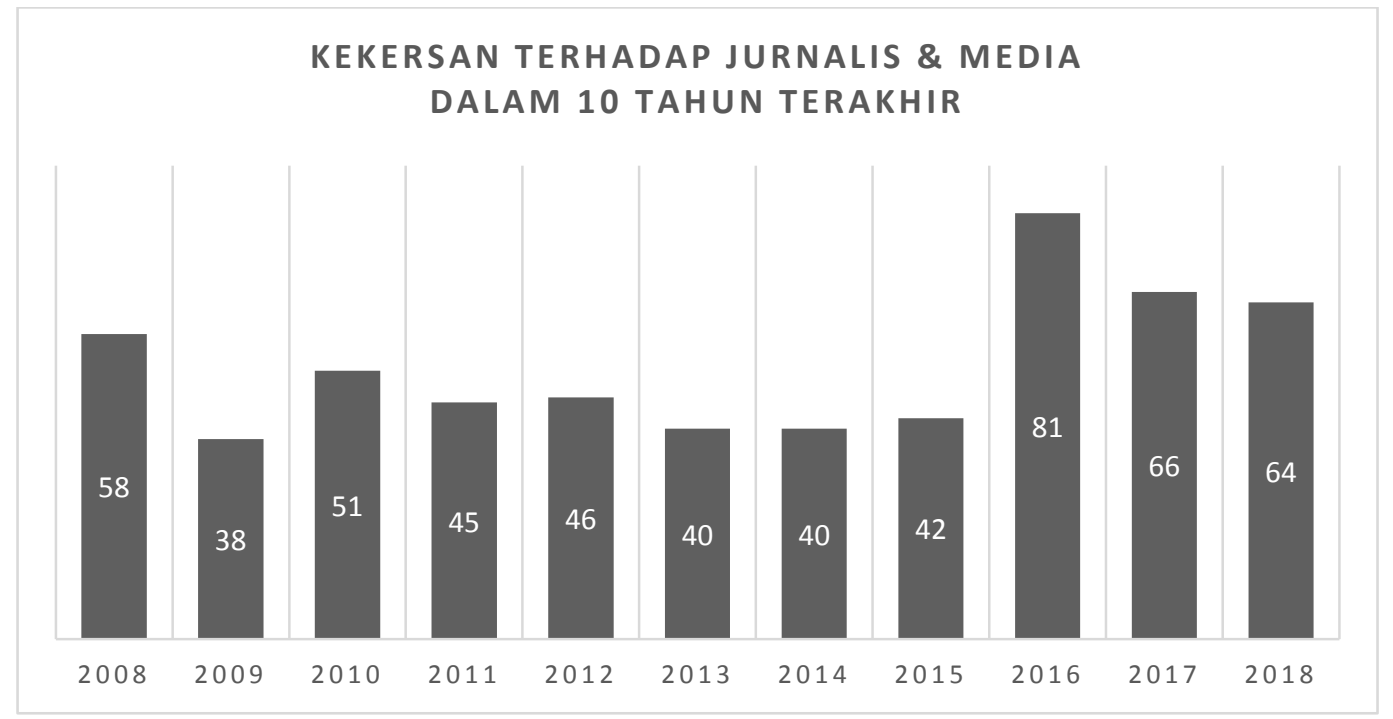

Sumber : Diolah dari Bidang Advokasi AJI Indonesia 2008-2018

Diagram 1. Kekerasan terhadap jurnalis dan media dalam 10 tahun terakhir

Kategorisasi kekerasan terhadap wartawan berdasarkan Pedoman Penanganan Kasus Kekerasan Terhadap Wartawan (Buku Saku Wartawan, 2017:164), meliputi a) kekerasan fisik, yang meliputi penganiayaan ringan, penganiayaan berat, penyiksaan, penyekapan, penculikan, dan pembunuhan; b) Kekerasan nonfisik, yang meliputi ancaman verbal, penghinaan, penggunaan kata-kata yang merendahkan, dan pelecehan; Perusakan peralatan liputan seperti kamera dan alat perekam; Upaya menghalangi kerja wartawan mencari, memperoleh, memiliki, menyimpan, mengolah, dan menyampaikan informasi, seperti merampas peralatan kerja wartawan atau tindakan lain yang merintangi wartawan sehingga tidak dapat memproses pekerjaan kewartawanannya.

Tidak sedikit wartawan yang mendapat ancaman fisik maupun nonfisik ketika menjalankan profesinya sebagai wartawan. Hal tersebut sering terjadi karena ketakutan seorang narasumber terhadap informasi yang dibeberkan wartawan melalui media massanya, ditambah lagi dengan sifat wartawan yang tidak mudah puas dengan informasi yang didapat, dan harus mencari infomasi dari berbagai pihak, maka resiko yang dihadapi wartawan semakin bertambah.

Selain itu, faktor lain yang memengaruhi kekerasan terhadap wartawan adalah faktor internal pada jurnalis, di antaranya inkompetensi, pelanggaran etika jurnalistik yang serius, kualitas SDM (tak sesuai standar perilaku), kecerobohan, terlalu pecaya diri secara berlebihan, dan keberpihakan media dan pemberitaan (Prasetyo, dalam Roosyana, 2019) Faktor internal yang disebut Prasetyo ini sebenarnya kesalahan wartawan sendiri yang harus mendapatkan banyak perhatian dari organisasi wartawan.

Karena itu untuk melancarkan tujuan dan fungsinya para wartawan kemudian membuat organisasi sebagai wadah penyalur aspirasi, sarana menentukan ide dan gagasan, maupun sebagai alat untuk menguatkan perannya dalam masyarakat. Hal itu sebagaimana pengertian organisasi secara umum yaitu unit sosial yang dikoordinasi secara sadar, terdiri atas dua individu atau lebih, dan berfungsi dalam suatu 


\section{Jurnal Komunikasi Nusantara}

e-ISSN. 2685-7650

Vol. 1 No. 1 (2019), pp 11-19

DOI: https://doi.org/10.33366/jkn.v1i1.4

dasar yang relatif terus-menerus guna mencapai satu atau serangkaian tujuan bersama (Robbins \& Judge, 2008:5)

Organisasi wartawan seperti Aliansi Jurnalis Independen (AJI), Persatuan Wartawan Indonesia (PWI), dan Ikatan Jurnalis Televisi Indonesia (IJTI) merupakan organisasi wartawan yang jelas dan telah diakui Dewan Pers, sehingga dalam membantu menyelesaikan kasus yang dihadapi oleh wartawan akan lebih mudah. Mereka juga memiliki beberapa tujuan organisasi misalnya perjuangan untuk mempertahankan kebebasan pers, meningkatkan profesionalisme jurnalis, dan meningkatkan kesejahteraan jurnalis.

Dewan Pers sendiri berfungsi sebagai pelindung kemerdekaan pers yang beranggotakan perwakilan organisasi wartawan, misalnya perwakilan AJI, PWI maupun perwakilan dari kepala perusahaan dan pimpinan perusahaan pers. Dengan adanya organisasi yang menaungi setiap tugasnya, seseorang akan lebih merasa aman dan tenang, karena dalam organisasi terdapat susunan atau struktur keanggotaan yang hierarkis dan memiliki hubungan satu sama lain. Dengan adanya hubungan yang hierarkis tersebut diharapkan pola komunikasi yang terjalin dapat efektif sesuai dengan maksud dan tujuan organisasi tersebut.

AJI memiliki cabang-cabang organisasi di beberapa daerah Indonesia, salah satunya adalah AJI Cabang Kota Malang. Bukan saja organisasi yang berfungsi menghimpun wartawan yang ingin bergabung, namun AJI juga difungsikan sebagai alat untuk mengadvokasi setiap anggotanya (wartawan) yang menghadapi masalah saat melakukan kegiatan jurnalistik.

Untuk AJI Malang beberapa kasus kekerasan terhadap jurnalis yang telah diadvokasi antara lain melalui beberapa berita: Meliput Pesawat Jatuh di Malang, Alat Kerja Jurnalis Dirampas (Aji, 2016), AJI Malang Kecam Aksi Pelemparan Gelas pada Wartawan (Detik, 2010), Kebebasan Pers: AJI Minta Penganiaya Rahman Patty Diadili (Sofii, 2013) dan beberapa kasus lainnya yang telah dimuat di media massa. Kasus lain yang tidak di publikasikan media tentu lebih banyak dari itu dan perlu diketahui publik melalui penelitian ini.

Dari berbagai permasalahan tersebut, perlu pola komunikasi yang baik untuk mengadvokasi masalah-masalah yang dihadapi wartawan. Advokasi merupakan proses yang terencana dan telah diatur sedemikian rupa untuk mencapai suatu tujuan hingga merubah kebijakan publik. Dalam advokasi yang di lakukan AJI Malang, tentu memiliki pola yang jelas sehingga membantu sukses tidaknya proses advokasi.

Dari hal tersebut, akan digunakan konsep pola komunikasi yang memiliki empat pola yaitu, pola komunikasi primer, pola komunikasi sekunder, pola komunikasi linier dan pola komunikasi sirkular. (Effendy dalam Alves, 2016). Dengan adanya proses yang jelas seperti yang dikemukakan Effendy, dari komunikasi dari perorangan hingga antar kelompok, tentu akan meningkatkan kesempatan untuk mencapai keberhasilan yang baik dalam manajemen pola komunikasi organisasi. Pelaksanaan fungsi struktural dalam teori tersebut juga sangat berpengaruh dalam melaksanakan perencanaan, analisis hingga memutuskan.

\section{Metode Penelitian}

Penelitian ini menggunakan jenis kualitatif karena ingin melihat dan mengungkap obyek penelitian dalam konteksnya sehingga akan didapatkan pemahaman yang mendalam (Yusuf, 2014:43). Penentuan informan berdasarkan kriteria yaitu mengetahui sejarah advokasi di AJI Malang, pernah menjabat sebagai Ketua atau pengurus inti, minimal 3 tahun aktif di AJI Malang, serta sampai sekarang masih aktif menjadi wartawan. Dari kriteria tersebut didapatkan tiga orang informan, yaitu Ketua AJI Malang Periode 2012-2015, Eko Widianto, Ketua AJI Malang Periode 2015-2018, Hari Istiawan, dan Sekretaris AJI Malang Periode 2015-2018, Abdul Malik. 


\section{Jurnal Komunikasi Nusantara}

e-ISSN. 2685-7650

Vol. 1 No. 1 (2019), pp 11-19

DOI: https://doi.org/10.33366/jkn.v1i1.4

\section{Hasil Dan Pembahasan}

\section{Pola Komunikasi Advokasi AJI Malang}

Komunikasi Organisasi sebenarnya tidak hanya berbicara dalam satu bidang organisasi, tetapi juga di dalamnya ada komunikasi interpersonal, komunikasi kelompok kecil, komunikasi bermedia melalui catatan-catatan juga memo internal organisasi. Semua kemungkinan komunikasi ini terjalin dan berjejaring sehingga membentuk sebuah pola di mana pola itu seringkali menjadi ciri khas cara berkomunikasi dalam organisai tersebut.

Selain itu organisasi juga sebagai tempat menyampaikan pesan-pesan antar anggota maupun media penyampai pesan kepada khalayak sehingga memiliki pola yang hierarkis antara satu dengan lainnya dan tidak bisa dilakukan secara masing-masing (Mulyana, dalam Ruliana, 2014:17). Menurut Effendy (dalam Alves, 2016), terdapat empat pola dalam mengomunikasikan pendapat dalam berorganisasi, yaitu primer, sekunder, linier, dan sekuler.

Meskipun Effendy membagi menjadi empat pola, tetapi sangat sulit menemukan sebuah organisasi yang hanya menjalankan satu saja pola komunikasi di dalamnya. Ketika melakukan analisis pada komunikasi organisasi yang dilakukan AJI Malang untuk mengadvokasu wartawannya, keempat pola tersebut saling berebut tempat dan tidak bisa dipisah-pisahkan. Tetapi untuk untuk Pola Komunikasi Linier memang agak kurang sehingga sulit sekali menjelaskan bagaimana pola ini digunakan oleh AJI Malang. Penjelasan mengenai keempat pola tersebut sebagai berikut.

1. Pola Komunikasi Primer

Pola komunikasi primer sebagai pola pertama dalam menjalankan komunikasi organisasi menjadi penting perannya untuk di lakukan setiap organisasi, termasuk Aliansi Jurnalis Independen (AJI) Malang dalam mengadvokasi wartawan. Pola komunikasi ini memaksimalkan komunikasi secara langsung baik verbal maupun nonverbal. Dijelaskan oleh Hartati (2013) bahwa Pola Komunikasi Primer merupakan pola paling awal yang dikembangkan oleh Aristoteles ketika Yunani masih berkomunikasi secara langsung.

Aliansi Jurnalis Independen (AJI) Malang tentu menggunakan pola komunikasi tersebut dalam setiap pertemuan atau rapat anggota. Dari hal tersebut, secara sadar maupun tidak Aliansi Jurnalis Independen (AJI) Malang akan melakukan komunikasi secara lisan maupun hanya dengan simbolsimbol (nonverbal) sebagai penekanan komunikasi verbal. Dari wawancara dengan Eko Widianto, dijelaskan bahwa mereka kerap melakukan kajian untuk membahas isu-isu kekerasan terhadap wartawan. Tidak jarang dari diskusi tersebut hadir pula wartawan yang menjadi korban kekerasan yang menjadi salah satu target advokasi oleh AJI.

"Kejadian (kekerasan terhadap wartawan) di Kota Malang tidak banyak, tetapi ada. Nah kita biasanya melakukan pendekatan personal dulu, kan sesama wartawan sehingga mereka mau menceritakan kejadiannya seperti apa. Dari sana kemudian kita kaji di tim internal, lalu kita komuniaksi lagi sampai mereka mau diadvokasi," (wawancara dengan Eko Widianto)

Dalam konteks pola komunikasi primer, kondisi tersebut merupakan sebuah contoh yang pas. Bisa dikatakan pola komunikasi primer ini adalah komunikasi yang mendasar karena dilakukan secara langsung dengan menggunakan bahasa verbal (bahasa ucap atau tulisan) dan non-verbal misalnya dengan melihat dan merasakan gerak tubuh dan mimik korban kekerasan wartawan. Selain kepada wartawan, AJI Malang juga berkoordinasi dengan media tempat di mana korban bekerja agar mendapatkan dukungan yang dibutuhkan. 


\section{Jurnal Komunikasi Nusantara}

e-ISSN. 2685-7650

Vol. 1 No. 1 (2019), pp 11-19

DOI: https://doi.org/10.33366/jkn.v1i1.4

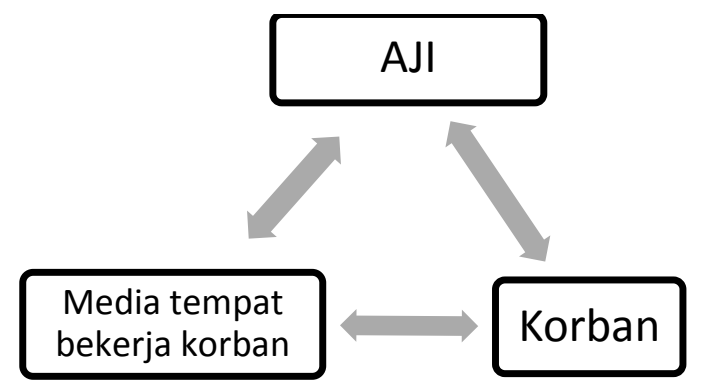

Diagram 2: Ilustrasi pola komunikasi primer yang dilakukan AJI Malang kepada wartawan korban kekerasan

\section{Pola Komunikasi Sekunder}

Pola Komunikasi Sekunder memanfaatkan alat atau media untuk menyampaikan pesan dari komunikator ke komunikan, persis sebagaimana komunikasi bermedia. Biasanya alat yang digunakan adalah media massa karena dipandang yang paling efektif menyebarkan informasi ke khalayak. Aliansi Jurnalis Independen (AJI) Malang melakukan pola ini sekaligus sebagai kampanye anti kekerasan terhadap wartawan. AJI Malang juga kerap membuat rilis pemberitaan yang dikirim ke beberapa media agar dimuat sehingga tujuan advokasi AJI berjalan.

Menurut Ketua AJI Malang, Hari Istiawan, pihaknya menggunakan media sebagai advokasi secara non litigasi atau tidak dengan jalur hukum. Jadi sifatnya hanya kampanye dan menginformasikan ke khalayak maupun sesama anggota untuk melakukan sesuatu, seperti aksi solidaritas atau sama-sama menulis berita yang berisi menolak kekerasan terhadap wartawan.

"Ya ini salah satu cara yang efektif agar masyarakat tahu juga bahwa ada kejadian wartawan mendapatkan perlakuan yang tidak semestinya. Upaya-upaya ini kami lakukan sebagai bentuk solidaritas kita sesame wartawan, apalagi AJI itu salah satu organisasi jurnalis yang independen dan berjuang sepenuhnya bersama wartawan" (Wawancara dengan Hari Istiawan).

Selain menggunakan media massa, AJI Malang juga memanfaatkan website organisasi guna mengajak masyarakat menyuarakan anti kekerasan terhadap wartawan, serta menyerukan pembelaan terhadap wartawan korban kekerasan. Beberapa pemberitaan tentang aksi menolak kekerasan yang pernah dilakukan oleh AJI Malang misalnya, di Kompas : AJI Malang Desak Adili Pelaku Pemukulan Jurnalis, di media kbr : Banyak Kekerasan Terhadap Wartawan, AJI Malang Buka Posko Pengaduan, dan di media internal AJI Malang : AJI Malang Tuntut Kapolres Pasuruan Kota Menindak Anggota Perampas Alat Kerja Wartawan.

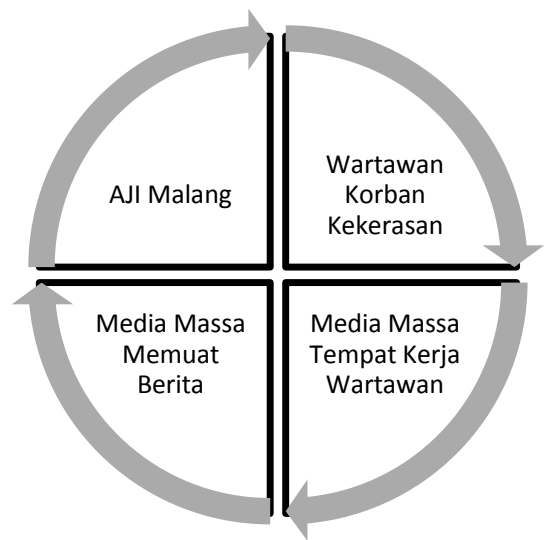

Diagram 3 : Ilustrasi Pola Komunikasi Sekunder yang dilakukan AJI Malang 


\section{Jurnal Komunikasi Nusantara}

e-ISSN. 2685-7650

Vol. 1 No. 1 (2019), pp 11-19

DOI: https://doi.org/10.33366/jkn.v1i1.4

\section{Pola Komunikasi Linier}

Pola komunikasi linier sebagai pola komunikasi secara horizontal memiliki peran dalam menyamakan persepsi antar anggota Aliansi Jurnalis Independen (AJI) Malang. Pola ini identik dengan komunikasi secara tatap muka (face to face) (Effendy, 2009 : 26). Aliansi Jurnalis Independen (AJI) Malang melakukan pola ini hanya untuk melakukan kajian secara mendalam terkait kasus-kasus kekerasan terhadap wartawan. Sehingga yang terjadi dalam pola ini tidak menyentuh secara langsung ke korban wartawan yang mendapatkan kekerasan tetapi lebih untuk mengakajinya dari berbagai sisi secara profesional bersama anggota AJI.

"Kalau kajian itu biasanya memang dari informal dulu, kita bicarakan di mana-mana kalau ada wartawan yang mendapatkan kekerasan atau ancaman. Kemudian kita sesama anggota AJI secara intens mengomunikasikannya termasuk mencari celah-celah bagaimana kita bisa membantu. Lalu dari informal dengan ngopi atau di WhatsApp Group kita bawa ke forum, di sana di bahas sampai deal arahnya mau kemana, baru kita melakukan aksi lebih lanjut" (wawancara dengan Eko Widianto)

"AJI Malang itu sering ngumpul-ngumpul, kadang informal kadang formal. Tetapi lebih banyak kita diskusi-diskusi itu santai sambil bercanda. Tetapi kalau ada kasus kekerasan terhadap wartawan, kami diskusinya santai tapi serius karena ini menyangkut concern kami di AJI. Cukup sering kalau kajian, bisa dikatakan punya agenda rutin," (wawancara dengan Abdul Malik)

Menarik disebutkan oleh narasumber adalah di keorganisasian AJI Malang, struktur organisasi berjalan jika dalam kondisi-kondisi formal jika berhubungan dengan instruksi ke AJI pusat. Dalam kajian harian, Ketua AJI dan jajaran pengurus inti, akan duduk bersama dengan anggota yang aktif (inti) maupun anggota lainnya dalam posisi yang sama. Mereka juga akan mendapatkan porsi berkomunikasi dan mengutarakan pendapat yang sama sehingga bisa digambarkan proses komunikasinya sebagai berikut :

4. Pola Komunikasi Sirkular

Pola komunikasi sirkular memiliki pola melingkar, atau tidak terputus antara komunikator dan komunikan. Penentu keberhasilan pola ini pada feedback yang di berikan komunikan. AJI Malang mengakui sering menggunakan pola sirkular karena dirasa lebih efektif dibanding pola yang lain. Dilihat dari struktur komunikator-komunikan yang ada, pola ini merupakan pola yang paling banyak digunakan komunitas-komunitas yang tidak menganggap struktur organisasi sebagai sesuatu yang sakral. Seperti yang disebutkan di pola linier, AJI Malang lebih melakukan komunikasi informal dibanding komunikasi formal.

Dalam pola komunikasi sirkular, AJI Malang melakukan komunikasi dengan korban, dengan sesama anggota AJI, dengan media massa tempat wartawan korban kekerasan bekerja, membuat press release terkait sikap AJI Malang, juga menghubungi beberapa rekan media untuk menyuarakan sikapnya melalui berita, baik cetak maupun dalam jaringan (daring). Semua komunikasi yang dilakukan AJI Malang bahkan bisa disebut komunikasi sirkular yang terus-terus saling menanggapi sehingga lebih berkembang.

Berdasarkan hasil penelitian, AJI Malang dalam menjalankan pola komunikasi sirkular antara lain adalah sebagai berikut : 


\section{Jurnal Komunikasi Nusantara}

e-ISSN. 2685-7650

Vol. 1 No. 1 (2019), pp 11-19

DOI: https://doi.org/10.33366/jkn.v1i1.4

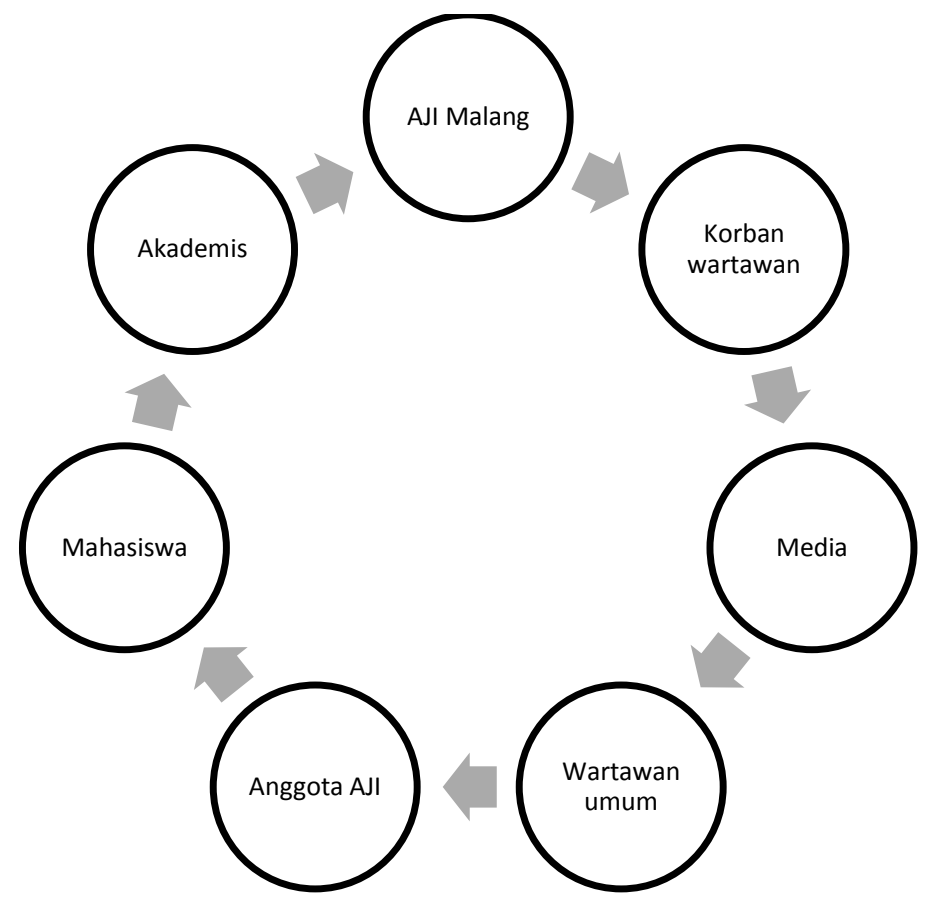

Diagram 5 : Orang-orang yang terlibat dalam sirkulasi obrolan AJI Malang terkait advokasi wartawan korban kekerasan

Ketua AJI Malang menambahkan, semua yang terlibat dalam pembicaraan ketika advokasi wartawan tidak duduk dalam satu waktu dan satu forum, tetapi menjalin komunikasi secara bergiliran sehingga semua informasi sampai ke AJI Malang. "Diskusinya macam-macam, kadang sesama anggota AJI, kadang sama wartawan se Malang, kadang juga ada stakeholder lain. Intinya advokasi menjadi salah bagian penting bagi perjalanan AJI, jadi kita akan terus memperjuangkannya", (wawancara dengan Hari Istiawan).

\section{Penghambat AJI Malang dalam Advokasi Wartawan}

Dalam mengadvokasi wartawan ada beberapa hambatan yang dirasakan oleh AJI Malang selama ini. Hambatan-hambatan ini seringkali tidak bisa dicari solusinya sehingga membuat aktivitas advokasi AJI Malang tidak berjalan. Beberapa hambatan bisa dijelaskan dengan rinci oleh AJI Malang, tapi sebagian lainnya tidak bisa dijelaskan dengan gamblang. Namun secara garis besar, hambatan ini bisa dibagi menjadi dua, yaitu internal dan eksternal.

\section{Faktor Internal}

Hambatan internal dalam mengadvokasi wartawan bersumber dari anggota Aliansi Jurnalis Independen (AJI) Malang sendiri. Misalnya anggota AJI Malang yang belum paham mengenai kode etik jurnalitik sehingga melanggar ketika liputan lalu mengakibatkan kekerasan. Hal ini sesuai dengan yang disayangkan oleh banyak pihak, seperti kata Ketua Dewan Pers, Yosep Stanley Adi Prasetyo di Buletin Dewan Pers (2017) bahwa kekerasan terhadap pers antara lain juga karena sikap tidak profesional wartawan, misalnya mamaksa narasumber untuk berbicara.

Prasetya mentakan hal itu karena ia merasa dituding kurang gesit karena dari 78 laporan ke Dewan Pers soal kekerasan terhadap wartawan, hanya 2-4 kasus saja yang ditangani. Kasusnya pun sama dengan yang dikatakan oleh narasumber dari AJI Malang. Menurut Eko Widianto dan Hari Istiawan, sepanjang proses advokasi berjalan, sebagian besar wartawan meminta kasusnya dihentikan sehingga advokasi yang dilakukan AJI Malang terkesan sia-sia. Prasetyo (2017) juga mengatakan hal yang 


\section{Jurnal Komunikasi Nusantara}

e-ISSN. 2685-7650

Vol. 1 No. 1 (2019), pp 11-19

DOI: https://doi.org/10.33366/jkn.v1i1.4

sama, bahwa secara nasional Dewan Pers banyak mengalami kendala ketika menangani kasus kekerasan wartawan karena wartawannya sendiri yang ingin menempuh jalan damai.

\section{Faktor Eksternal}

Faktor eksternal yang menjadi penghambat Aliansi Jurnalis Independen (AJI) Malang dalam mengadvokasi wartawan berasal dari pihak perusahaan pers yang tidak pro aktif membantu wartawan dalam melakukan advokasi, seperti halnya yang dijelaskan oleh Hakim (2013), bahwa banyak perusahaan pers yang kurang pro aktif dalam mengawal kasus kekerasan terhadap jurnalis. Berdasarkan hasil penelitian dengan Aliansi Jurnalis Independen (AJI) Malang, perusahaan pers justru menyerahkan kasus kepada organisasi pers seperti Aliansi Jurnalis Independen (AJI) Malang tanpa mengawal kasusnya dari sisi perusahaan. Selain itu, kondisi masyarakat yang masih belum memahami manfaat pers bebas tanpa kekerasan bagi mereka sehingga seringkali masyarakat abai terhadap kasuskasus semacam ini.

Solusi dari adanya beberapa hambatan ini, antara lain jelaskan oleh Ketua Umum Ikatan Jurnalis Televisi Indonesia (IJTI) Hendriana (2018) yaitu, pertama pers Indonesia harus professional karena ia menganggap Kekerasan terhadap seorang jurnalis bisa jadi diakibatkan menumpuknya kekesalan masyarakat karena buruknya produk jurnalistik dan kinerja seorang jurnalis. Kedua, Pers Indonesia harus memiliki kompetensi yang mumpuni, dalam artian kompetensi yang bisa dipertanggung-jawabkan akan mampu menjawab kebutuhan publik akan informasi yang akurat, bertanggungjawab dan berguna bagi masyarakat sehingga dapat menghindari gesekan dengan masyarakat.

\section{Kesimpulan}

Berdasarkan penelitian yang telah di lakukan, Aliansi Jurnalis Independen (AJI) Malang telah melakukan pola komunikasi dengan baik dari pola komunikasi primer, sekunder, linier dan sirkular. Meskipun secara pola sesuai dengan Standar Operasional Prosedure (SOP) yang telah di tentukan Aliansi Jurnalis Independen (AJI) Indonesia, namun di AJI Malang masih terdapat kendala. Misalnya tidak adanya perlindungan dari berbagai pihak termasuk dari perusahaan pers untuk melindungi wartawan saat proses advokasi berlangsung, juga wartawan yang lebih sering menginginkan kasusnya berhenti karena ada perasaan tidak aman dan tidak nyaman.

Solusi dari hambatan ini lebih mengarah pada kualitas internal wartawan di bandingkan mengkritisi kondisi di luar lingkup kewartawanan, yaitu dengan meningkatkan profesionalitas dan kompetensi wartawan itu sendiri sehingga dapat menghindari konflik dengan masyarakat, Tentunya dari kesimpulan ini diperlukan penelitian lebih lanjut mengenai hubungan wartawan dengan masyarakatnya apakah memang konflik berasal dari diri wartawan atau dari masyarakat dan oknum-oknum yang kerap menjadi lawan dari wartawan di lapangan.

\section{Daftar Pustaka}

Alves, Joao Pedro Ribeiro. 2016. Pola Komunikasi Organisasi Dalam Meningkatkan Citra Positif Perusahaan Umum (Perum) Jasa Tirta. Skripsi. Tidak diterbitkan. FISIP Unitri : Malang.

Aliansi Jurnalis Independen. 2018. 679 Kasus Kekerasan Terhadap Jurnalis. Diakses dari http://advokasi.aji.or.id, pada 11 April 2018.

Aliansi Jurnalis Independen. 2016. Meliput Pesawat Jatuh di Malang, Alat Kerja Jurnalis Dirampas. Diakses dari https://advokasi.aji.or.id/id/read/data-kekerasan/1057.html, pada 11 April 2018.

Detik. 2010. AJI Malang Kecam Aksi Pelemparan Gelas pada Wartawan diakses dari https://news.detik.com/berita-jawa-timur/1406123/aji-malang-kecam-aksi-pelemparan-gelas-padawartawan pada 15 April 2018. 


\section{Jurnal Komunikasi Nusantara}

e-ISSN. 2685-7650

Vol. 1 No. 1 (2019), pp 11-19

DOI: https://doi.org/10.33366/jkn.v1i1.4

Dewan Pers. 2018. Pedoman Penanganan Kasus Kekerasan Terhadap Wartawan. Dalam Buku Saku Wartawan. Jakarta: Dewan Pers

Dewan Pers. 2017. Wartawan Korban Kekerasan Kerap Pilih Damai. Dalam Buletin Etika Dewan Pers Edisi Mei 2017, Hal 6.

Effendy, Onong Uchjana. 2009. Ilmu Komunikasi Teori dan Praktek. Bandung: PT Remaja Rosdakarya.

Hakim, Imanuel. 2013. Upaya Perlindungan Hukum Kepada Wartawan Dari Tindak Kekerasan Pada Saat Menjalankan Tugas Jurnalistik (Studi Kasus Di Radio Elshinta Surabaya). Skripsi. FISIP Universitas Brawijaya Malang.

Hartati, Kalmi. 2013. Pola Komunikasi Antara Staf dan Lurah di Kantor Kelurahan Perangat Selatan Kecamatan Marangkayu Kabupaten Kutai Kartanegara. Jurnal Ilmu Komunikasi Unmul Vol 1 No 2 (2013) Hal 418-432.

Hendriana, Yadi. 2018. Kekerasan terhadap Jurnalis dan Profesionalisme Pers, dalam Jurnal Dewan Pers, edisi Juli 2018, Hal 12

Robbins, Stephen P \& Judge, Timothy A. 2008. Perilaku Organisasi, Buku 1 Edisi 12 (terjemahan). Jakarta:Salemba Empat

Roosyana, Rommy. 2019. Jurnalis dalam Ancaman Kekerasan. Diakses di https://beritagar.id/artikel/berita/jurnalis-dalam-ancaman-kekerasan pada 20 Mei 2019.

Ruliana, Poppy. 2014. Komunikasi Organisasi Teori dan Studi Kasus. Depok. PT.Rajagrafindo Persada.

Sofii, Muhammad. 2013. KEBEBASAN PERS: AJI Minta Penganiaya Rahman Patty Diadili. Diakses dari http://ajimalang.blogspot.com/2013/01/kebebasan-pers-aji-minta-penganiaya.html, pada 12 April 2018.

Yusuf, Prof. Dr. A. Muri. 2014. Metode Penelitian Kuantitatif, Kualitatif, \& Penelitian Gabungan. Jakarta: Penerbit Kencana 